\title{
COMPETÊNCIAS DOCENTES PARA O ENSINO SUPERIOR EM ADMINISTRAÇÃO: A ÓTICA DOS GRADUANDOS DE TRÊS UNIVERSIDADES DA BAHIA
}

\author{
Teaching competencies in administration higher education: \\ the view of three university undergraduates in Bahia
}

\author{
Jader Cristino de Souza-Silva* \\ Roberto Brazileiro Paixão** \\ Ana Paula da Silva*** \\ Marcus Vinícius Pereira Alves ${ }^{\star \star \star}$
}

\section{RESUMO}

Fruto de uma pesquisa mais ampla sobre docência superior no campo da Administração, este artigo buscou identificar quais as competências que compõem o perfil do professor excelente na área de Administração na ótica dos próprios estudantes de graduação em Administração. A pesquisa adotou uma abordagem qualiquantitativa, utilizando-se do Discurso do Sujeito Coletivo como estratégia de análise dos dados. 0 material empírico foi coletado junto a 87 estudantes de graduação de três universidades da Bahia. A partir da análise do material empírico, identificou-se 44 competências caracterizadoras do professor excelente na área de Administração, embora somente 22 delas foram mais profundamente analisadas devido ao quesito representatividade. Convém ressaltar que tais competências corroboram as pesquisas anteriores sobre o tema (MARSH, 1991; FRIEDMAN, 1999; LOWMAN, 2007; PAN et al., 2009; DELANEY et al., 2010) e, em certa medida, acrescentam detalhes a partir da apresentação dos discursos coletivos.

Palavras-chave: Competências do Professor Excelente. Docência em Administração. Ensino Superior.

\section{ABSTRACT}

As the result of wider research on higher education teaching in the field of Administration, this article sought to identify the competencies that make up the profile of the excellent professor in the area of Management from the perspective of undergraduate students in Business Administration. The research adopted a qualitative and quantitative approach, using the Collective Subject Discourse as a strategy for data analysis. The empirical material was collected from 87 undergraduate students from three universities in the state of Bahia. Based on the analysis of the empirical material, we identified 44 characteristics that characterize the outstanding teacher in the Administration area, although only 22 factors were further investigated due to their representation. It is worth noting that such factors corroborate previous research on the topic (MARSH, 1991; FRIEDMAN, 1999; LOWMAN, 2007; PAN et al., 2009; DELANEY et al., 2010) and, to some extent, add details arising from the presentation of collective discourses.

Keywords: Characteristics of the Excellent Professor. Teaching of Administration. Higher Education.

*Professor Pleno da Universidade do Estado da Bahia. Doutor em Aprendizagem Organizacional pela UFBa/ Michigan State Universty. E-mail: souzajader@gmail.com.

**Professor Adjunto do Núcleo de Pós-graduação em Administração da Universidade Federal da Bahia. Doutor em Administração pela Universidade Federal da Bahia.

***Graduado em Administração pela Universidade Salvador - Unifacs. 


\section{INTRODUÇÃO}

A o longo dos últimos anos, o ensino superior tem experimentado um vertiginoso processo de expansão, trazendo com ele algumas transformações que promovem uma diminuição de sua qualidade (KUHL et al., 2013). A Lei das Diretrizes e Bases da Educação de 1996 (BRASIL, 1996) pôs fim à legislação que determinava o modelo único de Universidade. Dessa forma, abriu-se uma interessante oportunidade para expansão do ensino superior no Brasil, sobretudo do setor privado (SOUZA-SILVA; DAVEL, 2005; SOUZA-SILVA, 2007; GUSMÃO, 2014).

Outros fatores contribuíram para tal ampliação. De fato, o ensino superior também se expandiu a partir do impacto do ensino médio que cresceu em virtude das políticas de investimento governamental que acabaram por promover significativo crescimento do sistema, especialmente a partir dos anos de 1990 (SIQUEIRA, 2001; SOUZA-SILVA, 2007). Por conta das deficiências do ensino superior público brasileiro e, principalmente, em função de sua incapacidade de absorver toda a demanda existente à época, as instituições de ensino superior (IES) privadas apresentaram-se como alternativa de absorção de tal demanda (TAKAHASHI, 2010), promovendo um acelerado aumento deste setor (SOUZA-SILVA, 2007; MANGANELLI, 2008). O curso de Administração foi um dos que mais cresceu neste contexto de expansão do ensino superior (SOUZA-SILVA, 2007). Existem, no Brasil, mais de 2.000 cursos, mais de 500 mil estudantes e mais de 25 mil professores de Administração (TORDINO, 2008).

Boa parte da expansão do ensino superior em Administração tem acontecido a partir de IES privadas, que demostram possuir uma orientação cada vez mais mercantilizada (SENO; KAPEL; VALADÃO JÚNIOR, 2014). Num contexto de ensino superior em Administração mercantilizado, o processo educacional passa a ser concebido como a prestação de um serviço eminentemente dirigido por concepções comercial e utilitarista da relação cliente-fornecedor (SOUZA-SILVA, 2007; SENO; KAPEL; VALADÃO JÚNIOR, 2014). Neste cenário, muitas vezes, a universidade acaba por não formar integralmente um indivíduo competentemente preparado para exercer sua profissão nem muito menos um cidadão crítico e reflexivo capaz de interferir e transformar as ordens estabelecidas. Assim, a consequência é um ensino superior em Administração cada vez mais empobrecido (PAIXÃO et al., 2014).

Neste contexto de empobrecimento da qualidade do ensino superior em Administração no Brasil, deve-se pensar em alguns fatores capazes de reverter esta situação. Há de se considerar ainda que boa parte dos estudantes de doutorado, entenda-se futuros professores na maioria, concentram o seu desenvolvimento mais em habilidades e conhecimentos referentes a disciplinas específicas do que em questões pedagógicas (BENNIS; O'TOOLE, 2005; SILVA; COSTA, 2014). Logo, num contexto onde a reflexão pedagógica sobre a formação do professor de Administração é preterida (GREENBERG; CLAIR; MACLEAN, 2007), pesquisar sobre as competências fundamentais de um professor diferenciado (positivamente) em Administração, bem como se dá o processo de formação de um excelente professor desta área é o mote de uma linha de pesquisa, da qual este artigo é um dos primeiros produtos.

Neste sentido, o problema de pesquisa é: a partir da visão dos alunos de graduação, quais as competências do professor excelente no ensino superior em Administração? O obje- 
tivo deste trabalho é identificar quais são as competências do professor excelente no ensino superior em Administração, a partir da visão dos graduandos do referido curso. É importante assinalar que não se tem o propósito de identificar as competências do professor excelente como pesquisador. Não que tais atributos não mereçam a devida atenção. No entanto, por opção teórico-metodológica a avaliação do docente, nesta investigação, limita-se ao seu trabalho como educador, ou seja, a sua atuação no processo de ensino-aprendizagem.

Esta pesquisa justifica-se, pois, apesar de existirem alguns estudos (MARSH, 1991; FRIEDMAN, 1999; LOWMAN, 2007; PAN et al., 2009; DELANEY et al., 2010) sobre o perfil do professor excelente ${ }^{1}$ (exemplar, diferenciado ou eficaz), não são muitos os trabalhos que se debruçaram em investigar as competências do professor eficaz na área específica da Administração. Neste sentido, no que concerne às competências do professor ideal, aquilo que já foi encontrado em outras áreas do conhecimento pode diferir quando se analisa um público diferente (REICHEL; ARNON, 2009; NOGUEIRA; CASA NOVA; CARVALHO, 2012).

Ademais, há uma pressão em relação às práticas pedagógicas dos professores de Administração, no sentido de que as mesmas estejam coerentes com negócios cada vez mais internacionais, mercados sem fronteiras, força de trabalho cada vez mais diversificada e uma constante e rápida atualização tecnológica. Em paralelo, as instituições de ensino também têm encampado mudanças nos formatos dos cursos em geral, abreviando-os, e intensificando o uso de tecnologias no ensino, notadamente na educação a distância (GREENBERG; CLAIR; MACLEAN, 2007; KUHL et al., 2013). Assim, este ambiente de mudanças requer uma reflexão sobre o quê os professores de Administração ensinam, como ensinam e porque certas escolhas pedagógicas são tomadas. Professores de Administração devem atentar-se para questões pedagógicas ligadas ao ensino da Administração, como sua postura enquanto professor, seu relacionamento com os estudantes e como educar para uma futura geração de líderes e cidadãos globais (FRIGA; BETTIS; SULLIVAN, 2004; GREENBERG; CLAIR; MACLEAN, 2007). Resumindo, é necessária uma reflexão por parte do professor de Administração sobre seu papel enquanto educadores.

Salienta-se que podem existir algumas ponderações sobre a capacidade dos estudantes para realizar a avaliação dos docentes. Tais ponderações partem de argumentos que os alunos não possuem experiência para contribuir com tal análise, devendo ser mais prudente deixar a avaliação dos docentes a cargo dos seus próprios pares (NOGUEIRA; CASA NOVA; CARVALHO, 2012). No entanto, a literatura já demonstrou que não há fundamento para esse argumento, configurando tal afirmativa como um mito (ALEAMONI, 1999; AXELROD, 2008; NOGUEIRA; CASA NOVA; CARVALHO, 2012). Assim, o material empírico dessa pesquisa foi coletado junto a 87 alunos do curso de Administração de três universidades baianas: Universidade Federal da Bahia (pública e federal); Universidade do Estado da Bahia (pública e estadual); e Universidade Salvador (privada).

1. Neste paper, professor excelente, bom professor, professor exemplar, professor ideal, professor eficaz e professor efetivo serão utilizados como termos intercambiáveis. 


\section{REFERENCIAL TEÓRICO}

\subsection{CONCEITOS DE COMPETENNCIA}

Ao se debruçar na literatura sobre o construto relacionado à competência, percebe-se um campo vasto e fecundo (FLEURY; FLEURY, 2004; GODOY et al., 2009; CRAWFORD; NAHMIAS, 2010). Apesar disso, muitos dos escritos acadêmicos sobre esse assunto acabam sendo influenciados por alguns autores seminais, tais como: McClelland (1973), Boyatzis (1982), Parry (1996), Le Boterf (2003), Zarifian (2003), dentre outros.

Segundo McClelland (1973), competências são características pessoais que podem promover uma performance superior na realização de uma tarefa. Boyatzis (1982) vê a competência como uma conjunção de conhecimentos, habilidades e atitudes que propiciam uma performance superior, mas sem desconsiderar o contexto no qual as competências são desempenhadas. Assim, para ele, os resultados alcançados pela competência estão em função de uma dinâmica interação entre as competências pessoais propriamente ditas, 0 desempenho no trabalho e o ambiente organizacional (NOGUEIRA; BASTOS, 2012).

Zarifian (2003, p.139-141), por sua vez, salienta que a competência pode ser definida como a tomada de iniciativa e o assumir de responsabilidade pelo indivíduo sobre problemas e eventos que ele enfrenta em situações profissionais. Já Le Borterf (2003) assinala que a competência é a consequência da interação de três componentes: 1) do saber agir; 2) do poder agir; e 3) do querer agir. 0 saber agir diz respeito ao saber fazer, isto é possuir habilidade conceitual sobre as etapas e recursos necessários ao desenvolvimento de uma determinada tarefa. 0 poder agir refere-se ao cenário propício capaz de facilitar a realização da tarefa. Finalmente, o querer agir diz respeito ao processo de motivação para desenvolver a tarefa (LE BOTERF, 2003, p. 158-161) isto implica ser encorajado por desafios, "[...] por uma autoimagem positiva que fortalece e incentiva a mobilização [...], bem como por um contexto de reconhecimento e confiança que estimula o trabalhador a assumir riscos" (NOGUEIRA; BASTOS, 2012, p. 227).

$O$ entendimento das competências como um conjunto de conhecimentos, habilidades e atitudes (PARRY, 1996), acrônimo CHA, representa uma síntese das definições apresentadas por McCleland (1973) e Boyatzis (1982). Autores da chamada escola francesa, como Zarifian (2003) e Le Boterf (2003), buscaram integrar o contexto (situações específicas) à mobilização do repertório de recursos de uma pessoa, ou seja, seus conhecimentos, habilidades e atitudes. Dessa forma, este trabalho considera as competências do professor excelente no contexto do "lecionar" Administração, ou seja, em sala de aula.

\subsection{COMPETÊNCIAS DO PROFESSOR EXCELENTE}

A literatura que se propõe a refletir sobre o perfil do professor excelente para 0 ensino superior divide-se, essencialmente, em dois grupos de autores que utilizam terminologias diferentes para discutir a questão. 0 primeiro deles prefere os termos: características, habilidades ou fatores para descrever o professor ideal (FRIEDMAN, 1999; KORTHAGEN, 2004; PAN et al., 2009; DELANEY et al., 2010). Outro conjunto de pesquisadores uti- 
liza-se da palavra competência para tratar dos atributos e componentes necessários ao exercício da docência (GROHMANN; RAMOS, 2012; NOGUEIRA; BASTOS, 2012; KUHL et al., 2013; SILVA; COSTA, 2014; PEREIRA; LOIOLA; GONDIM, 2016). Assim, esta seção buscou contemplar as duas perspectivas semânticas para caracterizar o perfil do docente excelente.

Em relação ao primeiro grupo, o professor eficaz é aquele que possui um conjunto de características que podem ser sintetizadas nas seguintes dimensões: empatia, conhecimento, relacionamento com o aluno, didática, administração da sala de aula, preparação para as aulas, motivação e contato com os pais (FRIEDMAN, 1999). A empatia diz respeito à habilidade de compreender as necessidades pessoais, psicológicas e escolares dos estudantes. Conhecimento trata-se do domínio do assunto a ser ensinado. Relacionamento com o aluno refere-se à boa relação que o professor deve estabelecer com seu aluno, sendo uma figura essencial para a promoção de um relacionamento positivo entre os estudantes. A didática, por sua vez, relaciona-se a capacidade do docente em criar uma metodologia de ensino capaz de facilitar e potencializar a aprendizagem. Administração da sala de aula refere-se à habilidade de o professor utilizar o diálogo, o aconselhamento e técnicas de avaliação para resolver as questões de disciplina, mantendo a ordem e o comportamento adequado ao aprendizado. A preparação para as aulas diz respeito ao tempo que o professor deve reservar para planejar, organizar e preparar adequadamente suas aulas. Motivação refere-se à capacidade de motivar o aluno. Finalmente, o contato com os pais é a atitude que o professor eficaz deve possuir de trabalhar em parceria com os pais, envolvendo-os em suas preocupações com seus estudantes, porém mais próxima do professor dos anos iniciais do ensino.

Brophy e Good (1986) salientam que, essencialmente, o bom professor deveria atentar para alguns fatores no sentido de promover a excelência da docência: a utilização de maior tempo de aprendizagem adequado ao ritmo dos estudantes; ativa integração entre professores e alunos; boa estrutura da turma; elevadas expectativas e uso constante de reforço positivo.

Chism (2006), também, investigou as características dos professores diferenciados. Especificamente, ele estudou os docentes que foram premiados em programas nos EUA. Tal pesquisador chegou, essencialmente, aos seguintes fatores que caracterizam 0 professor excelente: a) habilidades de comunicação; b) organização; c) padrões elevados de ensino; d) objetivos claros; e) entusiasmo; f) estratégias para envolver os estudantes; e g) foco no desenvolvimento de habilidades de alto nível.

Morrison e Mclntyre (1997), por sua vez, salientam que o professor ideal deve possuir quatro capacidades: a) a de criar um clima psicológico para a aprendizagem; b) a de identificar, planejar e avaliar as oportunidades de aprendizagem adequada; c) a de experimentar e descobrir abordagens mais convenientes para o ensino e a aprendizagem; e d) a capacidade de entender e empregar de forma construtiva o seu próprio comportamento.

Para Lowman (2007), o bom professor universitário é aquele que possui a habilidade de criar um estímulo intelectual e empatia interpessoal com seus estudantes. Essas duas habilidades são relativamente independentes. A efetividade de uma dessas duas categorias pode gerar êxito no magistério superior com alguns alunos e em determinadas turmas, 
mas quando um professor faz uso das duas habilidades, ele possui a probabilidade de ser considerado excelente em qualquer ambiente de ensino.

A habilidade de estímulo intelectual, por sua vez, é formada por dois componentes: a clareza da exposição do professor e o seu impacto emocional estimulante sobre os estudantes. A clareza é a capacidade que o professor possui de tornar a sua aula significativamente compreensível aos alunos que não possuem conhecimento aprofundado sobre o assunto que está sendo tratado (LOWMAN, 2007). Em outras palavras, os professores universitários excelentes devem ser capazes de expor seus pensamentos e suas ideias de forma a serem bem acessíveis aos não iniciados no entendimento de um determinado conceito ou fenômeno.

No entanto, não basta falar com clareza. É preciso que a exposição possua impacto emocionalmente estimulante. O professor universitário diferenciado deve ser alguém capaz de reter a atenção do aluno de tal modo a evitar distrações ou pensamentos diferentes, por parte dos alunos, ao que está sendo exposto. Neste sentido, o professor deve ser um ator em sala, concebendo a aula como uma oportunidade de interpretação, devendo bem utilizar sua voz, gestos, posturas e movimentos para manter a concentração e estimular a emoção dos estudantes (LOWMAN, 2007). Assim, ele deve perceber a sala de aula como arenas dramáticas, sendo que "alguns professores conseguem isso sendo extremamente entusiásticos, animados ou espirituosos, enquanto outros conseguem o mesmo efeito com um estilo mais calmo, mais sério e intenso, mas igualmente envolvente" (LOWMAN, 2007, p. 40).

Ao tratar da segunda habilidade (empatia interpessoal) do professor universitário exemplar, Lowman (2007) salienta que a sala de aula de uma universidade é uma arena interpessoal complexa, a qual abriga uma diversidade de emoções e sentimentos. Para ele, o professor que possui a habilidade de relacionamento interpessoal tem boa capacidade de se comunicar com os estudantes com vistas a elevar a motivação, a satisfação em aprender e a autonomia do aprendizado. Isso é alcançado de duas formas. A primeira é evitando promover emoções negativas, sobretudo a ansiedade e a raiva contra o docente. A segunda é estimular emoções positivas, tais como mostrar que respeita e considera os alunos como pessoas e os enxergar como parceiros no processo de ensino-aprendizagem com vistas ao bom desempenho.

Um componente adicional e importante para caracterizar o excelente professor é o seu domínio de novas tecnologias (KEMSHAL BELL, 2001). Perrenoud (2000) e Whale (2006) também defendem que os professores diferenciados não podem prescindir da inclusão da tecnologia na sala de aula.

Pan et al. (2009), por sua vez, ao analisarem os professores mais bem avaliados da Universidade Nacional de Cingapura sinalizaram alguns componentes relevantes para os docentes presentes neste ranking: a) despertam o interesse dos alunos; b) são acessíveis; c) têm capacidade de explicar claramente; d) dominam o conteúdo trabalhado; e) estão dispostos a ajudar; e f) são amigáveis e pacientes.

Nove características comportamentais do professor efetivo foram destacadas na pesquisa desenvolvida por Delaney e outros (2010). São elas: respeito, conhecimento, abordagem, envolvimento, comunicação, organização, responsabilidade, atuação profissional e humor. Essas características sobressaíram num rol de 69 outras, em pesquisa feita com dezessete mil estudantes de graduação e pós-graduação. 
Nogueira, Casa Nova e Carvalho (2012) desenvolveram outro trabalho que buscou investigar o perfil do bom professor a partir da ótica do estudante de Contabilidade. Para isso, eles entrevistaram alunos de quatro universidades brasileiras. Quando analisados individualmente os fatores mais importantes para o bom professor, o domínio de conteúdo apareceu como a característica mais importante, seguida imediatamente pela capacidade de explicar. Neste sentido, o bom professor a partir da visão dos estudantes de Contabilidade é aquele que domina bem o conteúdo, além de possuir a habilidade de transmiti-lo claramente aos estudantes. Outros componentes destacados pelos estudantes foram: a ligação entre teoria e prática e a preparação prévia da aula (NOGUEIRA; CASA NOVA; CARVALHO, 2012). Em complemento, os autores formularam quatro construtos que sintetizam o bom professor: a) relacionamento; b) planejamento, conhecimento e didática; c) tecnologia; e d) atributos pessoais. 0 relacionamento foi o que apresentou maior peso na análise dos autores, seguido do planejamento, conhecimento e didática e, ainda, da tecnologia. A pesquisa de Nogueira, Casa Nova e Carvalho (2012) de certo modo ratifica os trabalhos de Lowman (2007) em relação às características de domínio do conhecimento e didática, mas sinalizam para outros fatores importantes que a nova geração de alunos valoriza, a exemplo da questão tecnológica, presente também em Perrenoud (2000), Kemshal Bell (2001) e Whale (2006).

O trabalho de Bauer (2004), pioneiro na investigação do perfil do professor excelente do ensino superior em Administração, identificou, a partir da visão dos alunos, sete características fundamentais: a) domínio do conteúdo/conhecimento; b) didática/capacidade de transmissão; c) interesse pelo aluno; d) relacionamento professor/aluno; e) associação do conteúdo à realidade/conhecimento prático; f) interesse/entusiasmo pelo conteúdo; e g) capacidade de motivar os alunos.

Há autores que preferem o termo competências para tratar das características essenciais ao exercício da docência no campo da Administração. Por exemplo, Silva e Costa (2014) defendem que a formação do professor na área de Administração não deve prescindir de cinco saberes essenciais (competências): 1) saberes epistemológicos e metodológicos; 2) saberes teóricos; 3) saberes da prática docente; 4) saberes da produção escrita; 5) saberes da prática de pesquisa.

Nogueira e Bastos (2012) realizaram uma investigação, apresentando as competências observadas nos professores pesquisados em uma faculdade de Administração particular em São Paulo. Segundo esses autores, os docentes possuem as seguintes competências: 1) comprometimento com a efetiva aprendizagem dos alunos; 2) domínio dos conteúdos das disciplinas ministradas; 3) explicitação dos conceitos e da teoria e sua aplicação ao universo da Universidade; 4) comunicação clara que facilita a compreensão dos alunos; 5) disponibilidade para explicar e tirar dúvidas; 6) promoção e integração da participação coletiva e individual dos alunos; 7) utilização de metodologias que motivem a aprendizagem; utilização de meios e recursos que facilitem a aprendizagem; 8) facilitação da aprendizagem pelo respeito à heterogeneidade dos alunos; 9) orientação de alunos com o objetivo de superar suas dificuldades; 10) integração dos conteúdos dos programas das disciplinas ao longo do curso; 11) promoção da participação dos alunos durante as aulas; 12) articulação das disciplinas com outras áreas/disciplinas do curso; 13) atendimento às necessidades pessoais. 


\section{O Quadro 1 sintetiza a contribuição teórica dos autores já mencionados que inves- tigaram as competências do professor excelente.}

\section{Quadro 1 - Algumas pesquisas sobre as Competências do Professor Excelente}

\begin{tabular}{|c|c|}
\hline Autor & Contribuição Teórica \\
\hline Friedman (1999) & $\begin{array}{l}\text { O professor eficaz é aquele que possui as seguintes características: empatia, conhecimento, } \\
\text { relacionamento com o aluno, didática, administração da sala de aula, preparação para as aulas, } \\
\text { motivação e contato com os pais. }\end{array}$ \\
\hline Brophy e Good (1986) & $\begin{array}{l}\text { O bom professor deve atentar para alguns fatores para promover a excelência da docência: a } \\
\text { utilização de maior tempo de aprendizagem adequado ao ritmo dos estudantes; ativa integração } \\
\text { entre os professores e alunos; boa estrutura da turma; elevadas expectativas e uso constante de } \\
\text { reforço positivo. }\end{array}$ \\
\hline Chism (2006) & $\begin{array}{l}\text { O professor excelente possui o seguinte perfil: habilidades de comunicação; organização; } \\
\text { padrões elevados de ensino; objetivos claros; entusiasmo; estratégias para envolver os } \\
\text { estudantes; foco no desenvolvimento de habilidades de alto nível. }\end{array}$ \\
\hline Morrison e Mclntyre (1997) & $\begin{array}{l}\text { O professor ideal deve possuir quatro capacidades: criar um clima psicológico para a } \\
\text { aprendizagem; identificar, planejar e avaliar as oportunidades de aprendizagem adequadas; } \\
\text { experimentar e descobrir abordagens mais convenientes para o ensino e a aprendizagem; } \\
\text { capacidade de entender e empregar de forma construtiva o seu próprio comportamento. }\end{array}$ \\
\hline Lowman (2007) & $\begin{array}{l}\text { O bom professor universitário é aquele que possui a habilidade de criar um estímulo intelectual e } \\
\text { empatia interpessoal com seus estudantes. Essas duas habilidades são relativamente } \\
\text { independentes. Para ele, a efetividade de uma dessas duas categorias pode gerar êxito no } \\
\text { magistério superior com alguns alunos e em determinadas turmas, mas quando um professor faz } \\
\text { uso das duas habilidades, ele possui a probabilidade de ser considerado excelente em qualquer } \\
\text { ambiente de ensino. }\end{array}$ \\
\hline $\begin{array}{l}\text { Kemshal Bell (2001); Perrenoud } \\
\text { (2000); Whale (2006) }\end{array}$ & $\begin{array}{c}\text { Para eles, um componente importante para caracterizar o excelente professor, no momento } \\
\text { atual, é o seu domínio de novas tecnologias. }\end{array}$ \\
\hline Pan et al (2009) & $\begin{array}{l}\text { Para este autor, o professor diferenciado deve: despertar o interesse dos alunos; ser acessivel; } \\
\text { ter a capacidade de explicar claramente; possuir domínio do conteúdo; estar disposto a ajudar; e } \\
\text { ser amigável e paciente. }\end{array}$ \\
\hline Delaney e outros (2010) & $\begin{array}{l}\text { Nove características comportamentais do professor efetivo foram destacadas na pesquisa } \\
\text { desenvolvida por Delaney e outros (2010). São elas: respeito, conhecimento, abordagem, } \\
\text { envolvimento, comunicação, organização, responsabilidade, atuação profissional e humor. }\end{array}$ \\
\hline $\begin{array}{l}\text { Nogueira, Casa Nova e Carvalho } \\
\qquad(2012)\end{array}$ & $\begin{array}{l}\text { Quando analisados individualmente os fatores mais importantes para o bom professor, o } \\
\text { domínio de conteúdo apareceu como a característica mais importante seguida imediatamente } \\
\text { pela capacidade de explicar. Outros componentes destacados foram: a ligação entre teoria e } \\
\text { prática e a preparação prévia da aula. Em complemento, os autores utilizaram a análise fatorial } \\
\text { para a construção de construtos a partir das características do bom professor. Assim, eles } \\
\text { obtiveram quatro construtos que sintetizam o bom professor: relacionamento; planejamento, } \\
\text { conhecimento e didática; tecnologia; atributos pessoais. }\end{array}$ \\
\hline Bauer (2004) & $\begin{array}{l}\text { Ele identificou, na visão dos alunos, sete características fundamentais de um professor ideal na } \\
\text { área de Administração: domínio do conteúdo/conhecimento; didática/capacidade de } \\
\text { transmissão; interesse pelo aluno; relacionamento professor/aluno; associação do conteúdo à } \\
\text { realidade/conhecimento prático; interesse/entusiasmo pelo conteúdo; capacidade de motivar os } \\
\text { alunos. }\end{array}$ \\
\hline Silva e Costa (2014) & $\begin{array}{l}\text { A formação do professor na área de Administração não deve prescindir de cinco saberes } \\
\text { essenciais: 1) saberes epistemológicos e metodológicos; 2) saberes teóricos; 3) saberes da } \\
\text { prática docente; 4) saberes da produção escrita; 5) saberes da prática de pesquisa. }\end{array}$ \\
\hline Nogueira e Bastos (2012) & $\begin{array}{l}\text { Competências docentes encontradas na investigação dos autores: 1) comprometimento com a } \\
\text { efetiva aprendizagem dos alunos; 2) domínio dos conteúdos das disciplinas ministradas; } 3 \text { ) } \\
\text { explicitação dos conceitos e da teoria e sua aplicação ao universo da Universidade; 4) } \\
\text { comunicação clara que facilita a compreensão dos alunos; 5) disponibilidade para explicar e tirar } \\
\text { dúvidas; } 6 \text { ) promoção e integração da participação coletiva e individual dos alunos; 7) utilização } \\
\text { de metodologias que motivem a aprendizagem; utilização de meios e recursos que facilitem a } \\
\text { aprendizagem; 8) facilitação da aprendizagem pelo respeito à heterogeneidade dos alunos; } 9 \text { ) } \\
\text { orientação de alunos com o objetivo de superar suas dificuldades; 10) integração dos conteúdos } \\
\text { dos programas das disciplinas ao longo do curso; 11) promoção da participação dos alunos } \\
\text { durante as aulas; 12) articulação das disciplinas com outras áreas/disciplinas do curso; 13) } \\
\text { atendimento às necessidades pessoais. }\end{array}$ \\
\hline
\end{tabular}


Outra tentativa de caracterizar o professor de Administração foi realizada por Greenberg, Clair e Maclean (2007), utilizando, metaforicamente, as figuras mitológicas gregas de Atena (foco no conhecimento), Prometeu (ênfase na orientação) e Asclépio (ênfase na emoção). Esta caracterização difere das apresentadas, no Quadro 1, uma vez que são mais gerais, sem identificar aspectos cotidianos e funcionais do professor.

Professores considerados no arquétipo da deusa Atena, são definidos como facilitadores para o desenvolvimento cognitivo dos seus alunos. O principal objetivo para os mesmos é ensinar aos estudantes uma disciplina específica, um conteúdo específico, uma teoria, que vai auxiliá-los a desenvolver melhor uma determinada tarefa ou função. Por exemplo, professores de finanças que concentram seus esforços num conteúdo específico da área. O professor é um expert no assunto e a aquisição de conhecimentos por parte dos alunos é vista como principal meta tangível dos professores deste arquétipo, sendo questões humanas ligadas às emoções não tão valorizadas no processo pedagógico (GREENBERG; CLAIR; MACLEAN, 2007).

A ênfase na orientação é característica do arquétipo do deus Prometeu. Este professor pode ser considerado mais um mentor (facilitador, guia) e difere fundamentalmente do arquétipo ateniano em função do foco no desenvolvimento dos seus alunos de capacidades para atuar em equipes, de incrementar sua autoconfiança e de fortalecer sua autonomia em relação ao seu próprio aprendizado. Trata-se de um arquétipo que visa capacitar os alunos a serem responsáveis pelo seu aprendizado e, consequentemente, pelo seu futuro, ou seja, o desenvolvimento como cidadão. Está, assim, mais ligado ao entendimento das necessidades gerais dos alunos, do que ao dos conteúdos específicos que precisam aprender. 0 professor se aproxima do coach e assume uma posição de que na relação professor-aluno ambos estão em contínuo aprendizado (GREENBERG; CLAIR; MACLEAN, 2007).

Professores ligados ao arquétipo do Asclépio buscam atender aos alunos nas suas necessidades emocionais e psicológicas. Assumem a premissa de que o aprendizado só pode ocorrer quando os estudantes estão num processo de aprendizado emocionalmente seguro. A saúde emocional não é um fim em si mesmo, mas uma etapa fundamental para que outras etapas de aprendizagem ocorram. Assim, professores neste cenário, em geral, tentam criar um ambiente em sala de aula que permita aos estudantes visualizarem sua preocupação e disponibilidade em assisti-los emocionalmente, seja em grupos ou individualmente, aproximando-se de uma relação parental (GREENBERG; CLAIR; MACLEAN, 2007).

As diversas características do bom professor, mais específicas ou mais gerais, podem ser categorizadas em três domínios: a) relacionamento professor-aluno; b) métodos de ensino; e c) conhecimentos do professor (MIRON; MEVORACH, 2014). Em sua pesquisa com alunos de mestrado em Educação, Miron e Mevorach (2014) identificaram os domínios referentes ao relacionamento professor-aluno e aos conhecimentos do professor foram mais associados ao bom professor por alunos do segundo ano do curso, mais preocupados com o relacionamento e as parcerias com os professores, enquanto que os métodos de ensino 0 foram pelos do primeiro ano.

Pode-se considerar que, até hoje, duas questões permanecem não respondidas (HAMACHEK, 1999): a) quais são as qualidades essenciais de um professor?; e b) como se pode ajudar pessoas a se tornarem bons professores? Talvez estas questões levem a diferentes respostas em função dos múltiplos contextos onde os professores são inseridos, 
ou mesmo nem seja possível formular uma definição para o bom professor (KORTHAGEN, 2004), contudo um modelo de análise pode contribuir para as reflexões em relação às perguntas formuladas.

Para Korthagen (2004), o framework deveria conter diferentes níveis de análise, que fundamentalmente vão ser diferentes entre si. Este autor propõe um modelo de análise em seis níveis, do mais externo ao ser humano ao mais íntimo do seu ser. Os níveis são: ambiente; comportamento; competências; crenças; identidade; e missão. Apenas os níveis mais externos seriam diretamente observáveis, como o ambiente (a classe, os estudantes, a escola) e o comportamento dos professores. As competências influenciam o comportamento, representando um potencial para um dado comportamento, mas não o comportamento em si, dado que dependem das circunstâncias nas quais são efetivamente postas em prática e, na sequência, expressas em comportamento. As crenças do professor determinam as competências. A maneira como as pessoas entendem a si próprias e seus propósitos de vida compõem os dois níveis mais profundos do modelo (KORTHAGEN, 2004). As pesquisas apresentadas nesta seção concentram a atenção nos três primeiros níveis deste modelo, uma vez que os níveis da identidade e da missão, como destaca Korthagen (2004), são de difícil evidenciação.

\section{PROCEDIMENTOS METODOLÓGICOS}

A presente pesquisa adotou uma abordagem qualiquantitativa e, como método de análise do material empírico, o Discurso do Sujeito Coletivo (DSC). O DSC foi desenvolvido por dois pesquisadores da Universidade de São Paulo (Fernando Lefevre e Ana Maria Lefevre), na década de 1990, e se baseia na Teoria das Representações Sociais (JODELET, 1989).

O DSC consiste na representação qualitativa do pensamento coletivo, agregando as manifestações análogas de pessoas distintas em um único discurso-síntese (LEFEVRE; LEFEVRE; TEIXEIRA, 2000). Para isso, os atores da pesquisa são escolhidos com base na sua familiaridade com o tema (LEFEVRE; LEFEVRE, 2005).

O Discurso do Sujeito Coletivo privilegia a natureza qualitativa e quantitativa da pesquisa (LEFEVRE; LEFEVRE; TEIXEIRA, 2000; LEFEVRE; LEFEVRE, 2005). Qualitativa, pois, baseando-se na Teoria das Representações Sociais, pretende resgatar as ideias socialmente partilhadas. Neste sentido, o método busca privilegiar todas as ideias de uma representação social; não apenas as que são mais presentes, mas também, aquelas menos presentes, buscando apresentar, de forma plena, o espectro de diversas concepções e ideias que constam no discurso de uma dada representação social analisada. A natureza quantitativa do DSC pode englobar duas variantes quantificáveis: intensidade e amplitude.

A primeira imputa o percentual de indivíduos que contribuíram com suas expressões-chave relativas às ideias centrais semelhantes ou complementares, para a construção dos DSCs. Com isso, o pesquisador consegue ler quais discursos coletivos são mais frequentes no estudo. Em outras palavras, a intensidade permite constatar o grau de compartilhamento das representações sociais numa determinada população investigada. A amplitude mensura a presença do DSC, levando em conta o campo ou universo pesquisado, ou seja, conside- 
rando características distintas do grupo investigado (gênero, idade, escolaridade etc.). 0 tratamento quantitativo do material empírico coletado limitou-se à análise da variante intensidade, possibilitando constatar o grau de compartilhamento das representações sociais na amostra investigada. Esta opção metodológica justifica-se uma vez que este trabalho não objetiva identificar diferenças ou similaridades entre aspectos distintos de caracterização da amostra (TEIXEIRA; LEFEVRE, 2008; LEFEVRE; LEFEVRE, 2012).

O DSC baseia-se em três operadores: as expressões-chave (ECH); a ideias centrais (IC); e o discurso do sujeito coletivo (DSC) propriamente dito. As expressões-chave são partes contínuas ou descontínuas extraídas literalmente do discurso dos entrevistados e que revelam a essência do conteúdo do depoimento. Já a ideia central é um resumo dos conteúdos de uma categoria de expressões-chave. Em outras palavras, é uma expressão linguística que sintetiza o real conteúdo das expressões-chave. O Discurso do Sujeito Coletivo propriamente dito, por sua vez, trata-se da reunião de todas as expressões-chave agrupadas por categorias ou ideias centrais que reúne o conteúdo de uma representação social. Trata-se do discurso-síntese escrito na primeira pessoa do singular (LEFEVRE; LEFEVRE, 2012).

O DSC como estratégia metodológica usa questões abertas para colher os discursos dos entrevistados de modo a potencializar a rica, fluída e livre expressão dos respondentes (PAIXÃO et al., 2013). No que se refere ao total da amostra para investigações utilizando o Discurso do Sujeito Coletivo, não existe um número mínimo necessário (LEFEVRE; LEFEVRE, 2006). Para investigações que busquem apenas uma validação interna, Lefevre e Lefevre (2006) sugerem de 10 a 20 entrevistas com o objetivo de construção de um DSC.

\subsection{OPERACIONALIZAÇÃO DA PESQUISA}

A partir de uma pesquisa mais ampla sobre docência no ensino superior em Administração no Brasil, o público escolhido para este artigo em específico foi formado por 87 estudantes universitários em Administração de três universidades da Bahia, sendo duas públicas (Universidade do Estado da Bahia - Uneb e Universidade Federal da Bahia - Ufba) e uma privada (Universidade Salvador - Unifacs). Do total dos 87 respondentes, 43 eram estudantes da Uneb, 28 da Unifacs e 16 da Ufba. Dos alunos, 71 foram entrevistados face a face (entrevista presencial) e 16 receberam o questionário em formato digital, via e-mail. A coleta do material empírico teve um recorte temporal no período de outubro a dezembro de 2013.

O cabeçalho do questionário continha informações do objetivo da pesquisa e do seu caráter sigiloso de modo a deixar os alunos mais à vontade para responder as indagações apresentadas. Foi feita, também, uma solicitação aos respondentes para que fossem os mais analíticos e detalhistas possíveis para, assim, potencializar a construção dos discursos. 0 questionário constava de duas partes. Na primeira, os estudantes de graduação responderam a perguntas que tratavam de informações pessoais (nome, idade, sexo, semestre). Em seguida, haviam as perguntas relacionadas à docência no ensino superior em Administração, inclusive a que trata do perfil do professor excelente. Neste artigo, foi analisada apenas uma questão presente no questionário, a saber: Todos nós temos a lembrança de um ou mais professores da graduação em Administração que são considerados excelentes professores. Em sua opinião, o que faz um professor ser considerado excelente? 
A criação dos DSCs seguiu as seguintes fases (todas manipuladas com o apoio dos programas Google Drive, MS Excel e MS Word): a) seleção de expressões-chave (ECH) que sintetizam a essência da resposta de cada depoente; b) criação de ideias-centrais identificadas como IC-A, IC-B, IC-C (...) até a IC-AV com base nas expressões-chave identificadas anteriormente; e c) criação dos discursos dos sujeitos coletivos a partir dos agrupamentos das expressões-chave de cada uma das categorias ou ideias centrais.

É relevante assinalar que o método do DSC prevê a elaboração dos Discursos do Sujeito Coletivos a partir de outro operador linguístico, a ancoragem (AC) que se refere à expressão de uma ideologia ou teoria que o entrevistado professa (LEFEVRE; LEFEVRE, 2012; PAIXÃO et al. , 2013). No entanto, não foi utilizado, nesta pesquisa, por compreender que não traria significativas contribuições à análise do material empírico.

A partir da análise do material empírico, identificaram-se quais são os fatores que caracterizam o perfil do docente excelente especificamente no ensino superior em Administração (graduação) em três universidades da Bahia. Mesmo sabendo da impossibilidade de generalizações a partir desta pesquisa, pretende-se que seus resultados forneçam informações relevantes para desencadear reflexões com vistas ao aprimoramento do magistério superior no campo da Administração.

\section{APRESENTAÇÃO E ANÁLISE DOS RESULTADOS}

Todos os estudantes entrevistados são provenientes de cursos presenciais. Em relação ao gênero, 37 (42,8\%) estudantes eram do sexo masculino, $45(51,7 \%)$ do sexo feminino e $5(5,7 \%)$ não quiseram se identificar. Quando questionados sobre o semestre em que estavam, os estudantes do $2^{\circ}, 4^{\circ}$ e $6^{\circ}$ semestres somaram $77 \%$ dos respondentes (Tabela 1).

Tabela 1 - Semestre em Curso dos Respondentes

\begin{tabular}{ccccccccccc}
\hline Semestres & $\mathbf{1}$ & $\mathbf{2}$ & $\mathbf{3}$ & $\mathbf{4}$ & $\mathbf{5}$ & $\mathbf{6}$ & $\mathbf{7}$ & $\mathbf{8}$ & $\mathbf{9}$ & $\mathbf{1 0}$ \\
\hline Freq. Abs. & 0 & 22 & $\mathbf{1}$ & 23 & 4 & 22 & 1 & 6 & 1 & 7 \\
Freq. \% & $0,00 \%$ & $25,30 \%$ & $1,10 \%$ & $26,40 \%$ & $4,60 \%$ & $25,30 \%$ & $1,10 \%$ & $6,90 \%$ & $1,10 \%$ & $8,00 \%$ \\
Freq. \% Acum. & $0,00 \%$ & $25,30 \%$ & $26,40 \%$ & $52,90 \%$ & $57,50 \%$ & $82,80 \%$ & $83,90 \%$ & $90,80 \%$ & $92,00 \%$ & $100,00 \%$ \\
\hline
\end{tabular}

Foi realizada a análise da frequência das expressões-chave (Tabela 2) em que os discursos individuais eram classificados de acordo com as ideias centrais (IC). Como uma única resposta pode conter mais de uma IC, o somatório da frequência das ideias centrais foi superior à quantidade de respostas obtidas válidas na questão analisada.

Das 44 ideias centrais encontradas, selecionou-se as de $A$ até $X$ (IC-A até IC-X). Elas representam aproximadamente $87 \%$ das ideias centrais contidas nos discursos dos respondentes, sendo escolhidas para análise mais detalhada e construção dos DSCs justamente devido ao quesito representatividade. 
Tabela 2 - Frequência por Ideias Centrais

\begin{tabular}{|c|c|c|c|c|}
\hline Categoria & Ideias Centrais & Freq. Abs. & Freq. \% & Freq.\% Acum. \\
\hline IC-A & Possuir didática & 36 & $14,00 \%$ & $14,00 \%$ \\
\hline IC-B & Possuir domínio do conteúdo da disciplina que leciona & 28 & $10,90 \%$ & $24,80 \%$ \\
\hline IC-C & $\begin{array}{l}\text { Possuir preocupação com o entendimento/aprendizado do } \\
\text { conteúdo pelo aluno }\end{array}$ & 19 & $7,40 \%$ & $32,20 \%$ \\
\hline IC-D & Demonstrar interesse/preocupação pelos alunos & 18 & $7,00 \%$ & $39,10 \%$ \\
\hline IC-E & Demonstrar a aplicabilidade dos conteúdos & 15 & $5,80 \%$ & $45,00 \%$ \\
\hline IC-F & Ser dinâmico ao dar aula & 12 & $4,70 \%$ & $49,60 \%$ \\
\hline IC-G & Ser pontual & 11 & $4,30 \%$ & $53,90 \%$ \\
\hline IC-H & Possuir um bom relacionamento com a turma & 10 & $3,90 \%$ & $57,80 \%$ \\
\hline IC-I & Possuir metodologias variadas de transmitir o conteúdo & 9 & $3,50 \%$ & $61,20 \%$ \\
\hline IC-J & Ser um líder & 8 & $3,10 \%$ & $64,30 \%$ \\
\hline IC-L & Demonstrar interesse/dedicação pela matéria & 7 & $2,70 \%$ & $67,10 \%$ \\
\hline IC-M & Ser assíduo & 7 & $2,70 \%$ & $69,80 \%$ \\
\hline IC-N & Ser acessível / solícito & 6 & $2,30 \%$ & $72,10 \%$ \\
\hline IC-O & Ser carismático/simpático & 6 & $2,30 \%$ & $74,40 \%$ \\
\hline IC-P & Ser comprometido com sua profissão de educador & 6 & $2,30 \%$ & $76,70 \%$ \\
\hline IC-Q & Organizar e planejar as aulas/disciplina & 5 & $1,90 \%$ & $78,70 \%$ \\
\hline IC-R & Comunicar-se bem & 4 & $1,60 \%$ & $80,20 \%$ \\
\hline IC-S & Ser humilde & 4 & $1,60 \%$ & $81,80 \%$ \\
\hline IC-T & Ser paciente/tranquilo & 4 & $1,60 \%$ & $84,50 \%$ \\
\hline IC-U & Ser objetivo & 3 & $1,20 \%$ & $82,90 \%$ \\
\hline IC-V & Cobrar ao máximo do aluno & 3 & $1,20 \%$ & $85,70 \%$ \\
\hline IC-X & Ser um exemplo de ser humano & 3 & $1,20 \%$ & $86,80 \%$ \\
\hline IC-Z & Cumprir o programa da disciplina & 2 & $0,80 \%$ & $87,60 \%$ \\
\hline IC-AA & Estar aberto ao diálogo & 2 & $0,80 \%$ & $88,40 \%$ \\
\hline IC-AB & Estimular os alunos ao aprendizado & 2 & $0,80 \%$ & $89,10 \%$ \\
\hline IC-AC & Motivação em ensinar & 2 & $0,80 \%$ & $89,90 \%$ \\
\hline IC-AD & Ser ético & 2 & $0,80 \%$ & $90,70 \%$ \\
\hline IC-AE & Ser inovador & 2 & $0,80 \%$ & $91,50 \%$ \\
\hline IC-AF & Ser respeitoso com os alunos & 2 & $0,80 \%$ & $92,20 \%$ \\
\hline IC-AG & Possuir a capacidade de ajudar e desenvolver o aluno & 2 & $0,80 \%$ & $93,00 \%$ \\
\hline IC-AH & Possuir dedicação/responsabilidade em ensinar & 2 & $0,80 \%$ & $93,80 \%$ \\
\hline $\mid \mathrm{C}-\mathrm{Al}$ & Transmitir experiência em Administração & 2 & $0,80 \%$ & $94,60 \%$ \\
\hline IC-AJ & Utilizar cases & 2 & $0,80 \%$ & $95,30 \%$ \\
\hline IC-AL & $\begin{array}{l}\text { Possuir clareza na avaliação e a capacidade de entender que } \\
\text { as avaliações são educativas }\end{array}$ & 2 & $0,80 \%$ & $96,10 \%$ \\
\hline IC-AM & Dar conselho de como atuar no mercado de trabalho & 1 & $0,40 \%$ & $96,50 \%$ \\
\hline IC-AN & Depositar confiança no êxito do aluno & 1 & $0,40 \%$ & $96,90 \%$ \\
\hline IC-AO & $\begin{array}{l}\text { Incentivar } o \text { aluno a desenvolver a capacidade de } \\
\text { administrar/empreender }\end{array}$ & 1 & $0,40 \%$ & $97,30 \%$ \\
\hline IC-AP & Possuir bom humor & 1 & $0,40 \%$ & $97,70 \%$ \\
\hline IC-AQ & Realizar avaliações contínuas & 1 & $0,40 \%$ & $98,10 \%$ \\
\hline IC-AR & Realizar aulas externas & 1 & $0,40 \%$ & $98,40 \%$ \\
\hline IC-AS & Ser eloquente & 1 & $0,40 \%$ & $98,80 \%$ \\
\hline IC-AT & Possuir conhecimento de mercado & 1 & $0,40 \%$ & $99,20 \%$ \\
\hline IC-AU & Transmitir a própria versão do mundo & 1 & $0,40 \%$ & $99,60 \%$ \\
\hline IC-AV & $\begin{array}{l}\text { Trazer para a aula assuntos correlacionados para enriquecer } \\
\text { a aprendizagem }\end{array}$ & 1 & $0,40 \%$ & $100,00 \%$ \\
\hline
\end{tabular}

Revista Organizações \& Sociedade - v. 25, n. 86, p. 457-484, jul./set. 2018 DOI 10.1590/1984-9250866 | ISSN Eletrônico - 1984-9230 | www.revistaoes.ufba.br 
No Quadro 2, é apresentado o Discurso do Sujeito Coletivo referente à IC-A. Para os entrevistados, o professor excelente em Administração é, fundamentalmente, aquele que possui didática. Esta ideia central responde por $14 \%$ de todas as expressões-chave das diferentes ideias centrais. Para os estudantes do curso de Administração entrevistados, um professor excelente é aquele que sabe ensinar com simplicidade e clareza, ou seja, transmite o conteúdo da melhor forma aos alunos, facilitando a compreensão. Além disso, ele expõe o assunto com exemplos, é detentor de boas técnicas de ensino e é dinâmico, tornando atraentes os temas abordados, envolvendo os alunos, bem como imprimindo leveza de modo a promover uma aula agradável e prazerosa.

Esta primeira ideia central é confirmada pela revisão de literatura, anteriormente, apresentada. Friedman (1999) enfatiza a didática como um componente importante para caracterizar o professor eficaz. Inclusive, o entendimento de Friedman (1999) aproxima-se muito ao daquele dos alunos entrevistados quando afirma que a didática se relaciona a capacidade do docente em criar uma metodologia de ensino capaz de facilitar e potencializar a aprendizagem. Lowman (2007) é outro autor que corrobora a importância da didática na construção do professor excelente quando sinaliza a clareza como um dos componentes da habilidade de estímulo intelectual que todo bom professor deve desenvolver. Nogueira, Casa Nova e Carvalho (2012) também enfatizam tal componente na caracterização do professor excelente, bem como Pan et al. (2009) quando argumentam que o professor diferenciado possui elevada capacidade de explicar claramente o conteúdo. Similarmente, esta ideia central é confirmada pela pesquisa de Silva e Costa (2014) que advogam a importância dos saberes da prática docente como competência do professor.

Quadro 2 - IC-A - Possuir didática

Um professor excelente é aquele que, primeiramente, sabe ensinar com clareza, sabe transmitir o conteúdo. Ele deve ter boa didática. Precisa ser didático durante as suas aulas. É aquele que sabe passar o conteúdo da melhor forma para seus alunos. Ele possui boas técnicas de ensino e transmite o assunto de maneira simples e clara, isto é, consegue passar as informações, o conteúdo de maneira que todos entendam. Além disso, ele consegue ter dinamismo para tornar os conteúdos mais atraentes. Ele consegue transferir o conteúdo com facilidade, de forma clara, participativa e agradável, envolvendo os alunos nos temas abordados, fazendo com que o aprendizado não seja um fardo, mas algo prazeroso. Um professor excelente é aquele que ensina todo conteúdo de maneira didática, sendo capaz de entrelaçar seu dom do ensino para que possa passar o assunto o mais claro possível aos seus alunos. Assim, aliando uma boa metodologia e técnicas de ensino, ele expõe o conteúdo com exemplos, deixando as aulas mais leves.

No Quadro 3, é apresentado o Discurso do Sujeito Coletivo da IC-B. Para os estudantes das três universidades pesquisadas. A IC-B enfatiza que para ser considerado excelente é fundamental que o professor possua domínio do conteúdo da disciplina que leciona. Dito de outra forma, ele deve possuir segurança e propriedade em relação ao assunto relacionado à disciplina que ministra. Essa característica do professor excelente na área de Administração é compartilhada pelo trabalho de Friedman (1999) quando diz que o professor eficaz deve possuir domínio do assunto a ser lecionado. Nogueira, Casa Nova e Carvalho (2012), por sua vez, enfatizam, em suas pesquisas, o domínio do conhecimento como o componente mais relevante dentre as características do professor ideal. Bauer (2004), também, sinaliza que o conhecimento aprofundado na área é o fator mais importante no perfil do docente eficaz. Juntamente com esses autores, estão Nogueira e Bastos (2012), advogando ser o 
domínio dos conteúdos das disciplinas ministradas uma das competências do docente, bem como Silva e Costa (2014) que realçam os saberes teóricos como competências essenciais à docência. Neste sentido, percebe-se que a IC-B corrobora a literatura científica sobre esse assunto.

Quadro 3 - IC-B - Possuir domínio do conteúdo da disciplina que leciona

Ter domínio do conteúdo é fundamental. Acredito que ele deva ter domínio total do conteúdo de sua matéria, isto é conhecimento, segurança na informação, no assunto dado na disciplina/matéria que leciona. Ele deve realizar constante atualização dos conteúdos da matéria para demonstrar conhecimento dos assuntos. Assim, os professores excelentes são aqueles que passam confiança ao lecionar, dominam a disciplina, o conteúdo relevante que ele traz para a turma. Um professor excelente é aquele que, primeiramente, sabe o conteúdo.

O Discurso do Sujeito Coletivo da IC-C é apresentado no Quadro 4. Os estudantes entrevistados salientam que o professor excelente é aquele que se preocupa com o aprendizado dos alunos. Em outras palavras, este tipo de professor está preocupado não apenas em ensinar, mas em fazer com que seus estudantes compreendam de forma significativa 0 conteúdo da disciplina lecionada. Assim, ele procura ser solícito e disponível para esclarecer as dúvidas e ouvir os alunos, bem como identificar as dificuldades dos seus estudantes e monitorar se o aluno está aprendendo ou não. Neste sentido, percebe-se que, para os entrevistados, o professor excelente é alguém cuidadoso com seus discípulos, preocupando-se seriamente com seu aprendizado. Na revisão de literatura realizada, a única pesquisa que compartilha com a ideia central C é a investigação de Nogueira e Bastos (2012) que assinala que os docentes devem possuir a competência de se comprometer com a efetiva aprendizagem dos alunos.

Quadro 4 - IC-C - Possuir preocupação com o entendimento/aprendizado do conteúdo pelo aluno

O professor excelente é aquele que tem preocupação se os alunos estão entendendo, esclarece as dúvidas. Ele considera as dificuldades individuais dos alunos. Procuram entender, ouvir e sanar as dificuldades da turma. Tem interesse no aprendizado do aluno, ou seja, no resultado. Em outras palavras, o que faz um professor ser considerado excelente é quando ele busca sempre verificar o entendimento dos alunos e proporciona condições legais e necessárias para o entendimento dos mesmos. Quando possui a capacidade de investir intelectualmente no aluno. É quando o professor se preocupa se o aluno está aprendendo ou não. É solícito e disponível, constantemente, para tirar qualquer dúvida dos discentes com paciência e de forma educada. Ele está disposto a responder os questionamentos que não ficaram esclarecidos sem fazer disto algo 'vazio', mas preocupando-se, realmente, em tirar a dúvida do aluno. Ele, também, cobra atenção e ajuda a manter toda a turma na mesma concentração. Aplica os estímulos que motivam o aluno a aprender até mesmo aquelas disciplinas que este último possui grande dificuldade de entendimento ou falta de interesse. Além disso, para ser excelente, o professor precisa ser capaz de identificar quais alunos possuem maiores dificuldades de aprendizagem para que os ajude a se desenvolverem e, busque, como educador, promover o equilíbrio em nível de conhecimento entre todos os seus alunos. Para isso, é necessário que os professores promovam mecanismos de interação entre os alunos e eles mesmos de modo que todos se ajudem nessa jornada.

Demonstrar interesse/preocupação pelos alunos é tratado, no Quadro 5, como uma importante característica do professor excelente. Esta ideia central (IC-D) confirma as afirmações de Bauer (2004) que, também, salienta o interesse pelo aluno como um importante fator caracterizador do professor ideal. 
Quadro 5 - IC-D - Demonstrar interesse/preocupação pelos alunos

Um professor excelente é atencioso com os alunos, auxiliando-os dentro e fora de sala de aula. Deve mostrar interesse por eles, saber ouvi-los, tirar suas dúvidas e demonstrar comprometimento e compromisso com a turma. Assim, ele tem preocupação e é atento as necessidades dos alunos. O que marca é a dedicação que os professores têm com os alunos, o comprometimento, a preocupação mais com a formação do que no passar o aluno.

O Quadro 6 trata do discurso do sujeito coletivo da IC-E. Demonstrar a aplicabilidade dos conteúdos é outro componente que caracteriza o professor excelente e significa que ele realiza a conexão da teoria com a prática, ou seja, sabe contextualizar o assunto, demonstrando, a partir de exemplos práticos, a aplicabilidade dos conteúdos ensinados em sala de aula. Para os respondentes, esta forma de lecionar torna a aprendizagem mais atrativa, pois mostra a relação da teoria com a vida cotidiana. Em outras palavras, o professor excelente preocupa-se em mostrar como as teorias são usadas concretamente no mundo empresarial, contribuindo com uma visão mais profissional para os estudantes. Esse fator, também, é considerado como importante no perfil do docente ideal na pesquisa de Nogueira, Casa Nova e Carvalho (2012), bem como no trabalho de Bauer (2004) conforme visto na revisão da literatura.

Quadro 6 - IC-E - Demonstrar a aplicabilidade dos conteúdos

O professor excelente faz uma relação da teoria com a prática, relaciona o assunto com a realidade. Esta maneira de exposição da aula torna o aprendizado mais atrativo. Assim, ele utiliza uma metodologia que mistura teoria e prática. Leva para a sala de aula exemplos de aplicabilidade dos assuntos, torna o conhecimento prático, promove a utilização prática dos conteúdos, estimula que o aluno coloque o que aprendeu em prática. Assim, ele mostra a relação do conteúdo com a vida, trazendo a teoria para a realidade prática, aplicando o conteúdo em situações diversas. Mostra como as teorias que estou estudando foram usadas em grandes empresas, dando ao aluno uma visão além da simples absorção de conteúdo, mas uma visão profissional. Assim, o professor excelente transmite o conteúdo de modo que o mesmo faça sentido em um determinado contexto, aproximando-o da minha realidade.

A ideia central F (IC-F) apresentada no Quadro 7, refere-se à característica do ser dinâmico ao dar aula. Para os respondentes, isto significa que o professor excelente na área de Administração procura realizar aulas e atividades dinâmicas com seus alunos, isto é, expõe os conteúdos sem monotonia, torna a aula menos enfadonha, eliminando a resistência do aluno à disciplina e ao professor. Esta ideia central assemelha-se à característica impacto emocionalmente estimulante salientado por Lowman (2007) que adjetiva o professor como diferenciado. Para Lowman (2007), o bom professor é alguém capaz de reter a atenção do aluno ao que está sendo exposto. Dessa forma, o professor deve ser um ator em sala, concebendo a aula como uma oportunidade de interpretação, utilizando bem sua voz, gestos, posturas e movimentos para, de forma dinâmica, manter a concentração e estimular a emoção dos estudantes (LOWMAN, 2007).

Quadro 7 - IC-F - Ser dinâmico ao dar aula

Ele deve ser dinâmico ao dar a aula. Procurar fazer aulas e atividades dinâmicas com a turma. 0 professor excelente é aquele que se preocupa em expor o conteúdo de modo dinâmico, aproxima-se dos alunos e apresenta uma aula dinâmica, quebrando a monotonia da sala de aula. Se o professor não tiver uma boa dinâmica, o aluno cria resistência à matéria e ao professor. 
A ideia central G (IC-G) (Ser pontual), apresentada no Quadro 8, é outro fator importante no entendimento dos estudantes pesquisados para o professor excelente. Esta característica não é diretamente apontada por nenhuma investigação da revisão de literatura, mas sinaliza que o professor considerado excelente é alguém que, também, cumpre com a responsabilidade de chegar no horário estipulado pela instituição para ministrar sua aula. Ao analisar a frequência por ideia central, percebe-se que a IC-G responde por 4,3\% de todas as expressões-chave dos estudantes de Administração entrevistados. Tal ideia central aproxima-se da frequência da IC-F (Ser dinâmico ao dar aula) e possui maior frequência do que a IC-H (Ter bom relacionamento com a turma), demonstrando que, para os entrevistados, ser pontual é até mais relevante do que possuir bom relacionamento com a turma.

Quadro 8 - IC-G - Ser pontual

Acredito que ele deva cumprir horários, ter pontualidade.

O Quadro 9 apresenta o DSC da IC-H (Ter um bom relacionamento com a turma). Para os alunos entrevistados, o excelente professor é quem tem boa relação interpessoal com a sua turma. Em outras palavras, possui uma relação respeitosa e próxima com seus estudantes, interagindo, sendo afeito à comunicação, facilitando, assim, a troca de ideias e experiências. A IC-H confirma os achados de Friedman (1999) que diz que o professor ideal estabelece boa relação com seu aluno, sendo uma figura fundamental no relacionamento positivo entre os estudantes. Os resultados de Brophy e Good (1986) também corroboram a IC-H quando dizem que o bom professor é aquele que possui ativa integração com seus alunos. Lowman (2007), por sua vez, assinala a empatia interpessoal como a fundamental habilidade do bom professor. Para ele, o professor que possuir a habilidade de relacionamento interpessoal tem boa capacidade de se comunicar com os estudantes com vistas a elevar a motivação, a satisfação em aprender e a autonomia do aprendizado.

Quadro 9 - IC-G - Possuir um bom relacionamento com a turma

Possuir um bom relacionamento com a turma, ou seja, uma boa relação interpessoal com os alunos, com o grupo. Acredito que ele deva ter boa dinâmica de interação com a turma no que diz respeito a questões do dia a dia. Uma relação respeitosa, porém próxima dos alunos. O professor excelente consegue interagir com a turma, ser afeito à comunicação com aluno, ser amigo da turma, ter uma boa relação, sabendo lidar com as pessoas. Finalmente, é importantíssimo que haja grande interação entre alunos e professores, permitindo assim, trocas de ideias e experiências.

O Discurso do Sujeito Coletivo referente à IC-I é apresentado no Quadro 10. Possuir metodologias variadas de transmitir o conteúdo é considerada a ideia central com a nona maior frequência de expressões-chave. Para os entrevistados, o professor excelente deve primar por variar as suas metodologias de transmissão do conteúdo, não ficando apenas preso a apresentação dos slides. Ele deve promover aulas diferenciadas através da utilização de distintas ferramentas e variadas formas de expressar o assunto da aula. As pesquisas de Morrinson e McIntyre (1997) possuem relativa aproximação com a IC-I quando dizem que o bom professor possui a característica de experimentar e descobrir abordagens mais convenientes para o ensino e à aprendizagem. Outros autores que se aproximam da IC-I são 
Nogueira e Bastos (2012) quando assinalam a utilização de metodologias, meios e recursos que motivem e facilitem a aprendizagem como uma competência essencial à docência. Essa ideia central também corrobora a pesquisa de Silva e Costa (2014) quando advogam os saberes da prática docente como competência central à docência.

Quadro 10 - IC-I - Possuir metodologias variadas de transmitir o conteúdo

Acredito que o excelente professor deva ter metodologias variadas de passar o conteúdo. É aquele que utiliza de diversas metodologias de ensino para fazer com que seus alunos absorvam a matéria. Através da diversificação dos tipos de aula não ficam presos aos slides, promovem aulas diferenciadas e diversificadas, utilizando várias ferramentas e diferentes formas de expressar o conteúdo.

O Quadro 11 apresenta o Discurso do Sujeito Coletivo da IC-J: Ser um líder. Os respondentes sinalizam que o excelente professor deve ser um líder em sala de aula, isto é, alguém que possa conduzir a turma de forma coerente. Assim, o docente diferenciado possui controle, domínio sobre a turma. A postura de liderança contribui para que ele possa adquirir respeito perante os alunos. De certa forma, a IC-J possui relação com o trabalho de Friedman (1999) quando ele salienta que o bom professor deve possuir uma boa administração da sala de aula que se refere à habilidade de o professor utilizar o diálogo, o aconselhamento e técnicas de avaliação para resolver as questões de disciplina, mantendo a ordem e o comportamento adequado ao aprendizado.

Quadro 11 - IC-J - Ser um líder

O professor excelente é um líder, tem liderança, tem postura de um líder, ou seja, a facilidade de conduzir a turma, de ter controle sobre a turma. O domínio da turma, sua postura em sala de aula, sua liderança faz com que ele adquira respeito dos alunos.

O discurso do sujeito coletivo da IC-L (Demonstrar interesse/dedicação pela matéria) é apresentado no Quadro 12. Para os entrevistados, possuir amor, dedicação, interesse e comprometimento pela matéria que leciona são outros componentes importantes para um professor ser considerado excelente. Dentre as pesquisas que integram a revisão de literatura de nossa investigação, o trabalho de Bauer (2004) ratifica a IC- $L$ ao assinalar que o interesse/entusiasmo pelo conteúdo é um fator de diferenciação do professor.

Quadro 12 - IC-L - Demonstrar interesse/dedicação pela matéria

O que faz um professor ser considerado excelente é quando o professor tem dedicação com a disciplina, tem interesse e comprometimento pela matéria, ou seja, possui o amor visível pela disciplina que leciona.

Outra característica importante do professor excelente é ser assíduo que é apresentado no discurso do sujeito coletivo do Quadro 13 e referente à IC-M. Essa é uma característica que não foi encontrada no referencial teórico levantado para esta investigação. 
Quadro 13 - IC-M - Ser assíduo

Acredito que ele deva ter presença, ou seja, ser assíduo, ter comprometimento com a assiduidade.

Para um professor ser considerado excelente, não basta que ele possua um bom relacionamento com a turma conforme visto na $\mathrm{IC}-\mathrm{H}$. É importante que ele consiga, também, ser acessível, solícito, prestativo e disponível com as demandas dos alunos. Essa é uma ideia central que corrobora com os achados de Pan et al. (2009) que assinala que o professor diferenciado deve estar disposto a ajudar, bem como aproxima-se da investigação de Nogueira e Bastos (2012) quando afirmam a disponibilidade para explicar e tirar dúvida como uma competência docente.

Quadro 14 - IC-N - Ser acessível/solícito

É um professor de fácil acesso, demonstra-se uma pessoa acessível, solícita, prestativa e disponível para seus alunos.

O Discurso do Sujeito Coletivo da IC-O é apresentado no Quadro 15. Para os entrevistados, ser carismático e simpático com os estudantes é outro componente fundamental para ser considerado um professor excelente. A IC-O não é uma característica vista na revisão de literatura que caracteriza o professor excelente. Neste sentido, ela traz avanços para uma melhor compreensão de um docente diferenciado na área de Administração.

Quadro 15 - IC-O - Ser carismático/simpático

Acredito que ele deva ter simpatia e carisma com os aprendizes.

O Quadro 16 apresenta o discurso do sujeito coletivo da IC-P (Ser comprometido com a sua profissão de educador). Para os estudantes de Administração que foram entrevistados, para ser considerado um professor excelente, o docente necessita possuir compromisso com o exercício acadêmico de educador. $O$ educador não é aquele que apenas se preocupa em transmitir o conteúdo de sua disciplina, mas consegue extrapolar sendo um mentor de seu aluno e contribuir com sua formação intelectual e humanista. Essa não foi uma característica vista no referencial teórico realizado, significando também uma contribuição à literatura sobre 0 assunto

Quadro 16 - IC-P - Ser comprometido com sua profissão de educador

Um professor para ser considerado excelente deve, antes de tudo, ter compromisso com aquilo que faz, com seu ofício, seu trabalho, sua profissão, isto é, interesse pelo exercício acadêmico de educador.

Organizar e planejar as aulas/disciplina é a IC-Q apresentada no Quadro 17. Para os respondentes, o professor excelente na área de Administração é alguém que possui a atenção de planejar as aulas, buscando imprimir uma organização lógica para melhor conduzir sua disciplina. Neste sentido, ele é cuidadoso para escolher o material didático-pedagógico 
que adotará durante o semestre, bem como confecciona com esmero suas avaliações de aprendizagem. Esse componente que caracteriza o bom professor é encontrado na literatura sobre o assunto. Por exemplo, Lowman (2007) chama tal fator de Preparação para as aulas que se trata do tempo que o bom professor tem de dispor para planejar, organizar e preparar coerentemente suas aulas. Já Morrison e Mclntyre (1987) também enfatizam essa característica presente no Discurso do Sujeito Coletivo da IC-Q quando salientam que o professor ideal deve possuir a capacidade de identificar, planejar e avaliar as oportunidades de aprendizagem adequadas.

Quadro 17 - IC-Q - Organizar e planejar as aulas/disciplina

O professor excelente é o que possui aulas bem preparadas, lógica na condução da disciplina, ou seja, sabe combinar o conteúdo programático, as atividades em sala de aula, as provas e os trabalhos. É aquele que cuida da organização, planejamento das aulas e trabalhos, bem como realiza atividades bem construídas. Além disso, compromete-se com aulas bem preparadas, com o conteúdo, com o material indicado, com a elaboração das avaliações.

O Quadro 18 trata da IC-R que sinaliza que o professor excelente é alguém que se comunica bem, sendo detentor de uma linguagem atual e simples. Isso confere clareza à comunicação. A revisão de literatura corrobora esta característica do professor excelente a partir dos trabalhos de Chism (2006) e Delaney e outros (2010) quando eles assinalam a habilidade de comunicação como sendo um componente relevante para caracterizar o professor ideal. Similarmente, há a pesquisa de Nogueira e Bastos (2012) que faz referência à comunicação clara que facilita a compreensão dos alunos como uma relevante competência docente.

Quadro 18 - IC-R - Comunicar-se bem

O professor excelente é aquele que possui uma linguagem atual e simples. Possui uma boa oratória, comunicabilidade, isto é clareza na comunicação.

A ideia central S, referente ao discurso do sujeito coletivo exposto no Quadro 19, mostra que ser humilde é outro fator que qualifica o professor excelente. Para os respondentes, o docente ideal, além das outras características já mencionadas, deve também desenvolver a humildade. Os entrevistados entendem que o professor diferenciado é alguém que percebe que não é o único detentor do saber, permitindo-se aprender com as demais pessoas; não é arrogante, reconhece suas fraquezas e não se sente melhor do que ninguém. Este é um fator não assinalado no referencial teórico, trazendo, dessa forma, contribuições à literatura que trata das características do professor excelente no campo da Administração.

Quadro 19 - IC-S - Ser humilde

O professor, como qualquer profissional, torna-se excelente quando, acima de tudo, é humilde. A humildade que me refiro, é de o professor não ser arrogante. Ser humilde pressupõe que o professor, assim como qualquer indivíduo, reconheça suas fraquezas e saiba que ele não é o único detentor do saber e que estamos nesse mundo em constante aprendizado. Assim, ele compartilha seus conhecimentos com os demais indivíduos, ao mesmo tempo, que se permite aprender com as demais pessoas. Ter humildade é não se sentir melhor do que ninguém. 
O Quadro 20 apresenta o discurso do sujeito coletivo da IC-T. Os entrevistados assinalam que o professor excelente é paciente, possuindo um perfil calmo, passando o conteúdo com tranquilidade. É também uma característica que diretamente não é sinalizada por nenhum autor no referencial teórico.

\section{Quadro 20 - IC-T - Ser paciente/tranquilo}

O professor excelente é paciente, possui o perfil calmo na medida do possível. Passa o conteúdo com tranquilidade. Possui paciência

O sujeito coletivo da IC-U é apresentado no Quadro 21. Para os respondentes, o docente excelente é aquele que transmite o conteúdo da disciplina sem prolixidade, ou seja, consegue possuir objetividade em suas aulas. É um componente que também não é mencionado na revisão de literatura.

Quadro 21 - IC-U - Ser objetivo

O professor excelente possui objetividade nas aulas, ou seja, consegue transmitir o assunto de forma objetiva. Dito de outra forma, consegue passar a matéria para os seus alunos de forma objetiva.

Cobrar ao máximo do aluno refere-se à IC-V apresentada no Quadro 22. Para os respondentes, o bom professor é aquele que deve cobrar o máximo do aluno, mas que ao mesmo tempo dá o seu máximo. Assim, ele age com coerência. Essa característica é, em certa medida, salientada por Brophy e Good (1986) quando dizem que professor excelente possui elevadas expectativas em relação ao seu estudante.

Quadro 22 - IC-V - Cobrar ao máximo do aluno

O professor excelente é aquele que sempre exige o máximo do aluno, puxa ao máximo o aluno. Ele, porém, é coerente entre o assunto dado e o cobrado. Eu acho que, se o professor puxar ao máximo do aluno, ele tem que ensinar ao máximo.

Ser um exemplo de ser humano é a IC-X detalhada no Discurso do Sujeito Coletivo apresentado no Quadro 23. Os alunos do curso de Administração das três universidades pesquisadas salientam que o professor excelente também precisa ser um exemplo de ser humano, um espelho de conduta humana. É mais uma característica não enfatizada no referencial teórico pesquisado.

Quadro 23 - IC-X - Ser um exemplo de ser humano

O professor excelente tem que ser um exemplo de ser humano, um espelho para mim.

As ideias centrais A-X corroboram as pesquisas anteriores sobre o tema (MARSH, 1991; FRIEDMAN, 1999; BAUER, 2004; LOWMAN, 2007; PAN et al., 2009; DELANEY et al., 2010; NOGUEIRA; CASA NOVA; CARVALHO, 2012) e, em certa medida, acrescentam detalhes a partir da apresentação dos discursos coletivos. Por exemplo, Lowman (2007) 
assinala como habilidade do bom professor possuir um bom o relacionamento interpessoal. Esta investigação também corrobora este componente como sendo importante. No entanto, esta pesquisa não apresenta a mesma relevância enfatizada por Lowman (2007) para o fator de relacionamento interpessoal. Possuir um bom relacionamento com a turma responde por apenas 3,9\% do total de todas as expressões-chave do total dos respondentes.

Dentre as 22 ideias centrais selecionadas para o aprofundamento devido ao quesito representatividade quantitativa, seis delas apresentam-se melhor descritas e caracterizadas em relação aos estudos anteriores. Em outras palavras, em pesquisas passadas, tais ideias centrais são tratadas mais genericamente, isto é, são contempladas em outros fatores que as englobam. Já, nesta investigação, tais fatores emergem mais explicitamente a partir do discurso dos entrevistados e, por esse motivo, são discutidos de forma mais detalhada e específica. Neste sentido, as ideias centrais são: ser pontual (IC-G), ser assíduo (IC-M), ser humilde (IC-S), ser paciente/tranquilo (IC-T), ser objetivo (IC-U) e ser um exemplo de ser humano (IC-X). As IC-G e IC-M demostram que os estudantes das três universidades pesquisadas atribuem valor àqueles professores que são atentos às normas mais básicas da instituição a qual lecionam. Neste sentido, a representação social investigada confere relevância fundamental ao professor cumpridor das suas obrigações de pontualidade e assiduidade. A IC-S demonstra que os respondentes, também, valorizam aquele docente que é humilde e não se considera o único detentor do saber, permitindo-se aprender com outros indivíduos, inclusive com seus alunos. A IC-T sinaliza a paciência e a tranquilidade como características fundamentais no cotidiano do professor excelente. A objetividade em transmitir o conteúdo é outro componente valorizado pelos respondentes e exposto no discurso do sujeito coletivo da IC-U. Finalmente, a IC-X mostra que, para os entrevistados, além de todos os adjetivos mencionados, ser um exemplo de ser humano é um componente relevante para qualificar o professor excelente, demonstrando que, para ser um docente diferenciado, não basta desenvolver habilidades técnicas, mas também competências comportamentais e humanas.

Outra constatação é que os alunos entrevistados não fizeram qualquer menção à questão da tecnologia que, inclusive, é um dos elementos que caracteriza o bom professor na pesquisa de Nogueira; Casa Nova; Carvalho (2012), bem como nos trabalhos de Perrenoud (2000) Kemshal Bell (2001) e Whale (2006).

\section{CONCLUSÃO}

A presente investigação teve como propósito identificar quais as características que compõem o perfil do professor excelente na área de Administração na ótica dos próprios estudantes de graduação em Administração.

A pesquisa baseou-se em uma abordagem qualiquantitativa, utilizando-se do Discurso do Sujeito Coletivo como estratégia de análise dos dados. O material empírico coletado foi fruto do depoimento de 87 estudantes de graduação em resposta a seguinte pergunta: Todos nós temos a lembrança de um ou mais professores da graduação em Administração que são considerados excelentes professores. Em sua opinião, o que faz um professor ser considerado excelente? Tal indagação estava presente em um questionário mais extenso que 
encampa uma pesquisa mais ampla sobre docência superior no campo da Administração no Brasil.

A partir da análise do material empírico, encontrou-se 44 ideias centrais das quais, selecionou-se as de $A$ até $X$ (IC-A até IC-X). As IC selecionadas representam quase $87 \%$ das ideias centrais contidas nos discursos dos respondentes, sendo escolhidas para análise mais detalhada e construção dos DSCs justamente devido ao quesito representatividade.

Assim, o professor na área de Administração considerado excelente na perspectiva dos alunos é aquele que: tem didática, possui domínio do conteúdo da disciplina que leciona, é preocupado com o entendimento/aprendizado do conteúdo pelo aluno, demonstra interesse/preocupação pelos alunos, demonstra a aplicabilidade dos conteúdos, é dinâmico ao dar aula, é pontual, possui um bom relacionamento com a turma, faz uso de metodologias variadas de transmissão de conteúdo, é líder, demonstra interesse/dedicação pela matéria, é assíduo, é acessível/solícito, é carismático/simpático, é comprometido com sua profissão de educador, organiza e planeja as aulas/disciplina, comunica-se bem, é humilde, é paciente/ tranquilo, é objetivo, cobra ao máximo do aluno e é um exemplo de ser humano. Convém ressaltar que tais características corroboram as pesquisas anteriores sobre o tema (MARSH, 1991; FRIEDMAN, 1999; LOWMAN, 2007; PAN et al., 2009; DELANEY et al., 2010) e, em certa medida, acrescentam detalhes a partir da apresentação dos discursos coletivos.

Através das ideias centrais selecionadas e por meio de um exercício de agrupamento das mesmas, propõe-se três categorias de competências caracterizadoras do professor excelente, tendo como inspiração a categorização realizada por Miron e Mevorach (2014): 1) habilidades didático-pedagógicas, que remetem aos métodos de ensino; 2) habilidades humanistas, relativas ao relacionamento professor-aluno; e 3) habilidades conceituais, que se referem aos conhecimentos do professor sobre o conteúdo da disciplina que leciona.

As Habilidades Didático-Pedagógicas respondem por 42,5\% das expressões-chave presentes nos discursos dos respondentes e referem-se ao cuidado didático-pedagógico que o professor excelente no curso de Administração deve possuir. Em outras palavras, o professor excelente é alguém que possui não apenas o profundo domínio daquilo que leciona, mas também consegue transmitir aquilo que sabe com elevada clareza e lógica de raciocínio. Para isso, além de ser um exímio comunicador, o professor excelente necessita investir significativa parcela do seu tempo para planejar pedagogicamente suas aulas, contemplando diversas metodologias para transmitir de forma dinâmica e instigante o conteúdo de sua disciplina. Além disso, é aquele que não está preocupado apenas com o ensino, mas também com a aprendizagem, isto é, se seu aluno compreendeu de forma significativa aquilo que Ihe foi ensinado. Em outras palavras, são características ligadas ao domínio do método de ensino (MIRON; MEVORACH, 2014).

As Habilidades Humanistas integralizam 25,3\% de todas as expressões-chave dos depoimentos dos respondentes e referem-se à elevada capacidade que o professor excelente em Administração possui (ou deveria possuir) de relacionar-se com seus alunos, adotando a postura de um genuíno educador. Neste sentido, ele extrapola o papel de transmissor de conteúdos e exerce o papel de mentor e educador de gerações. Ele se torna um líder e parceiro do aluno no processo de ensino-aprendizagem, sendo, com o passar do tempo, um exemplo humano a ser seguido. As ideias centrais deste agrupamento aproximam-se das características do domínio relacionamento professor-aluno proposto por Miron e Mevorach 
(2014). Também tangenciam o arquétipo dos Deuses Prometeu e Asclépio (GREENBERG; CLAIR; MACLEAN, 2007), em função da maior ênfase no aluno nas questões emocionais e de orientação.

Tabela 3 - Categorias de Habilidades do Professor Excelente

\begin{tabular}{|c|c|c|c|c|}
\hline Categoria & Ideias Centrais & Freq. Abs. & Freq. $\%$ & Freq.\% Acum \\
\hline \multirow{12}{*}{$\begin{array}{l}\text { Habilidades Didático- } \\
\text { Pedagógicas }\end{array}$} & Possuir didática (IC-A) & 36 & $14,00 \%$ & \multirow{12}{*}{$42,50 \%$} \\
\hline & Possuir preocupação com o & & & \\
\hline & entendimento/aprendizado do & 19 & $7,40 \%$ & \\
\hline & conteúdo pelo aluno (IC-C) & & & \\
\hline & Ser dinâmico ao dar aula (IC-F) & 12 & $4,70 \%$ & \\
\hline & Ser pontual (IC-G) & 11 & $4,30 \%$ & \\
\hline & $\begin{array}{l}\text { Possuir metodologias variadas de } \\
\text { transmitir o conteúdo (IC-I) }\end{array}$ & 9 & $3,50 \%$ & \\
\hline & Ser assíduo (IC-M) & 7 & $2,70 \%$ & \\
\hline & $\begin{array}{l}\text { Organizar e planejar as aulas/disciplina } \\
\text { (IC-Q) }\end{array}$ & 5 & $1,90 \%$ & \\
\hline & Comunicar-se bem (IC-R) & 4 & $1,60 \%$ & \\
\hline & Ser objetivo (IC-U) & 3 & $1,20 \%$ & \\
\hline & Cobrar ao máximo do aluno (IC-V) & 3 & $1,20 \%$ & \\
\hline \multirow{9}{*}{ Habilidades Humanistas } & $\begin{array}{l}\text { Demonstrar interesse/preocupação } \\
\text { pelos alunos (IC-D) }\end{array}$ & 18 & $7,00 \%$ & \multirow{9}{*}{$25,30 \%$} \\
\hline & $\begin{array}{l}\text { Possuir um bom relacionamento com a } \\
\text { turma (IC-H) }\end{array}$ & 10 & $3,90 \%$ & \\
\hline & Ser um líder (IC-J) & 8 & $3,10 \%$ & \\
\hline & Ser acessível/solícito (IC-N) & 6 & $2,30 \%$ & \\
\hline & Ser carismático/simpático (IC-O) & 6 & $2,30 \%$ & \\
\hline & $\begin{array}{l}\text { Ser comprometido com sua profissão de } \\
\text { educador (IC-P) }\end{array}$ & 6 & $2,30 \%$ & \\
\hline & Ser humilde (IC-S) & 4 & $1,60 \%$ & \\
\hline & Ser paciente/tranquilo (IC-T) & 4 & $1,60 \%$ & \\
\hline & Ser um exemplo de ser humano (IC-X) & 3 & $1,20 \%$ & \\
\hline Habilidades Conceituais & $\begin{array}{l}\text { Possuir domínio do conteúdo da } \\
\text { disciplina que leciona (IC-B) }\end{array}$ & 28 & $10,90 \%$ & $19,40 \%$ \\
\hline
\end{tabular}

As Habilidades Conceituais somam 19,4\% das expressões-chave dos estudantes de Administração entrevistados e dizem respeito à expertise do professor em relação ao conteúdo da disciplina que ele está lecionando aos seus educandos. Quanto mais domínio e dedicação o docente possuir em relação à disciplina que ministra, mais ele se tornará um professor excelente. Nesta categoria, o domínio do conhecimento pelo professor é central (MIRON; MEVORACH, 2014). Por serem habilidades intrinsecamente ligadas ao conteúdo e seu domínio, aproximam-se do arquétipo da deusa Atena (GREENBERG; CLAIR; MACLEAN, 2007).

Convém ressaltar que as categorias para análise das competências representam um esforço analítico sem rigidez classificatória, uma vez que o contexto e a interpretação dos discursos poderão, em outras pesquisas, conduzir a diferentes conjuntos. Por outro lado, podem contribuir para a reflexão sobre os questionamentos apresentados por Korthagen (2004) acerca das qualidades essenciais de um professor e, principalmente, sobre a orien- 
tação que pode ser dada aos processos e programas de formação de novos professores de Administração.

É importante salientar que algumas ideias centrais podem representar, não apenas características de um professor excelente, mas, também, carências de qualquer natureza por parte dos alunos respondentes. Em outras palavras, algumas delas podem possuir um significado para além da caracterização do perfil de um docente ideal, podendo traduzir, por exemplo, uma carência afetivo-profissional dos entrevistados. Contudo, essa discussão não foi travada, aqui, pois não era este o propósito desta investigação. Pesquisas futuras podem explorar este possível viés.

Dentre as limitações dessa pesquisa, ressalta-se a impossibilidade de generalização das conclusões inerente à abordagem metodológica utilizada. Novas pesquisas de cunho eminentemente quantitativo podem auxiliar na identificação das características e possibilitar novos agrupamentos das mesmas. Além disso, a amostra utilizada também não é equitativa em termos numéricos, tendo mais participantes de universidades públicas. Assim, percebe-se a possibilidade de outros artigos analisarem a questão tendo como espectro dicotômico a segregação de alunos (público e privado). Outra pesquisa oportuna que desdobraria a presente investigação seria refletir sobre as trajetórias, caminhos e processos de aprendizagem mais adequados para a formação de um professor excelente no campo da Administração.

\section{REFERÊNCIAS}

ALEAMONI, L. M. Student Rating Myths Versus Research Facts From 1924 to 1998. Journal of Personnel Evaluation in Education, v. 13, n. 2, p.153-166, 1999.

AXELROD, P. Student perspectives on good teaching: what history reveals. Academic Matters, v. 14, n. 1, p. 61-74, 2006.

BAUER, M. A. L. Os Paradoxos da Administração: ambiguidades e desafios no ensino e aprendizagem de administração. Revista ANGRAD, São Paulo, v. 5, p. 41-58, 2004.

BENNIS, W. G.; O'TOOLE, J. How business schools lost their way. Harvard Business Review, v. 5, n. 83, p. 98-104, 2005.

BOYATZIS, R. E. The competent Manager. New York: John Wiley \& Sons, 1982.

BRASIL. Lei de Diretrizes e Bases da Educação Nacional. Lei n. 9394, 20 de dezembro de 1996.

BROPHY, J.; GOOD, T. Teacher behavior and student achievement. In: WITTROCK, M. Handbook of research on teaching. 3. ed. New York: Macmillan, p. 328-375, 1996.

CHISM, N. V. N. Teaching Awards: What do They Award? The Journal of Higher Education, v. 77, n. 4, p. 589-617, july/aug., 2006.

CRAWFORD, L.; NAHMIAS, A. H. Competencies for managing change. International Journal of Project Management, v. 28, n. 4, p. 405-412, 2010. 
DELANEY, J. et al. Students' perceptions of effective teaching in higher education. St. Johns', NL: Distance Education and Learning Technologies, 2010.

FLEURY, M.T.; FLEURY, A. Alinhando estratégia e competências. Revista de Administração de Empresas, São Paulo, v. 44, n. 1, p. 44-57, 2004.

FREITAS, M. E. A carne e os ossos do ofício acadêmico. Organizações \& Sociedade, Salvador, v. 14, n. 42, p. 187-191, 2007.

FRIEDMAN, I. A. Appropriate Teacher Work-Autonomy Scale. Educational and Psychological Measurement, v. 59, p. 58-76, 1999.

FRIGA, P. N.; BETTIS, R. A.; SULLIVAN, R. S. Mudanças no ensino em Administração: novas estratégias para o século XXI. Revista de Administração de Empresas, São Paulo, n. 1, v. 44, p. 96-115, 2004.

GODOY, A. S. et al. O desenvolvimento das competências de alunos formandos do curso de Administração: um estudo de modelagem de equações estruturais. Revista de Administração, São Paulo, v. 44, n. 3, p. 265-278, 2009.

GREENBERG, D. N.; CLAIR, J. A.; MACLEAN, T. L. Enacting the role of management professor: lessons from Athena, Promotheus, and Asclepius. Academy of Management Learning \& Education, v. 6, n. 4, p. 439-457, 2007.

GROHMANN, M. Z.; RAMOS, M. S. Competências docentes como antecedentes da avaliação de desempenho do professor: percepção de mestrandos de Administração. Avaliação, v. 17, n. 1, p. 65-86, 2012.

GUSMÃO, S. S. A formação do professor para o ensino superior em Administração. 2014. 102f. Dissertação (Mestrado em Administração). Universidade Salvador, Salvador, 2014.

HAMACHEK, D. Effective teachers: what they do, how they do it, and the importance of self-knowledge. In: LIPKA, R. P.; BRINTHAUPT, T. M. (Org.). The role of self in teacher development. New York: State University of New York Press, p. 189-224, 1999.

JODELET, D. Répresentations sociales: un domaine en expansion. In: JODELET, D. (Org.). Répresentations sociales. Paris: PUF, p.31-61, 1989.

KEMSHAL-BELL, G. The Online Teacher: Final Report prepared for the Project Steering Committee of the VET Teachers and On-line Learning Project. ITAM, ESD, TAFENSW. Department of Education and Training, TAFE NSW, 2001.

KORTHAGEN, F. A. J. In search of the essence of a good teacher: towards a more holistic approach in teacher education. Teaching and Teacher Education, v. 20, n. 1, p. 77-97, 2004.

KÜHL, M. R. et al. O valor das competências docentes no ensino da Administração. Revista de Administração, v. 48, n. 4, p. 783-799, 2013.

LE BOTERF, G. Desenvolvendo a competência dos profissionais. Porto Alegre: Bookman, 2003.

LEFEVRE, F.; LEFEVRE, A. M. C. Pesquisa de Representação Social: um enfoque qualiquantitativo. Brasília, DF: Liberlivro, 2. ed. 2012. 
LEFEVRE, F.; LEFEVRE, A. M. O sujeito coletivo que fala. Interface: Comunicação, Saúde e Educação. v. 10, n. 20, p. 517-524, 2006.

Depoimentos e discursos. Uma proposta de análise em pesquisa social. Brasília: Liberlivro Editora, 2005.

LEFEVRE, F.; LEFEVRE, A. M. C.; TEIXEIRA, J. J. V. O discurso do sujeito coletivo: uma nova abordagem metodológica em pesquisa qualitativa. Caxias do Sul: EDUCS, 2000.

LOWMAN, J. Dominando as técnicas de ensino. São Paulo: Atlas, 2007.

MANGANELLI, A. A mercantilização do ensino superior: um olhar para os trabalhadores docentes. 2008. 103 f. Monografia (Bacharelado em Ciências Econômicas) - Pontifícia Universidade Católica do Rio Grande do Sul. 2008.

MARSH, D. Privatization under Mrs. Teacher: a review of the literature. Public Administration, v. 69, n. 4, 1991.

MARSH, H. W.; HATTIE, J. The relation between research productivity and teaching effectiveness: complementary, antagonistic or independent constructs? The Journal of Higher Education, v. 73, n. 5, p. 603-641, sep./oct., 2002.

McCLELLAND, D. C. Testing for competence rather than for intelligence. American Psychologist, v. 28, p. 1-14, 1973.

MIRON, M.; MEVORACH, M. The "good professor" as perceived by experienced teachers who are graduate students. Journal of Education and Training Studies, v. 2, n. 3, p. 82-87, 2014.

MORRISON, A.; MCINTYRE, O. Os professores e o ensino. Rio de Janeiro: Imago, 1997.

NOGUEIRA, A. J. F. M.; BASTOS, F. C. Formação em administração: o GAP de competências entre alunos e professores. Revista de Gestão, São Paulo, v. 19, n. 2, p. 221-238, 2012.

NOGUEIRA, D. R.; CASA NOVA, S. P. C.; CARVALHO, R. C. O. O bom professor na perspectiva da geração Y: uma análise sob a percepção dos discentes de Ciências Contábeis. Enfoque, v. 31, p. 37-52, 2012.

PAIXÃO, R. B. et al. O constructo assédio moral na relação aluno-professor na perspectiva de professores universitários. Revista de Gestão, v. 21, n. 3, p. 415-432, 2014.

PAIXÃO, R. B. et al. Por que ocorre? Como lidar? A percepção de professores de graduação em Administração sobre o assédio moral. Revista de Administração, São Paulo, v. 48, n. 3, p. 516-529, 2013.

PAN, D. et al. Profiling teacher/teaching using descriptors derived from qualitative feedback: formative and summative applications. Research High Education, v. 50, n. 1, p. 73-100, 2009.

PARRY, S. The quest for competences: competencies studies can help you make HR decision, but the results are only as good as the study. Trainning, v. 33, 48-56, 1996.

PEREIRA, L. M. R.; LOIOLA, E.; GONDIM, S. M. G. Aprendizagem de competências, suporte à transferência de aprendizagem e desempenho docente: evidências de validação de escala e teste de relações. Organizações \& Sociedade, Salvador, v. 23, n. 78, p. 438-459, 2016. 
PERRENOUD, P. 10 Novas Competências para ensinar. Porto Alegre: Artmed, 2000.

REICHEL, N.; ARNON, S. A multicultural view of the good teacher in Israel. Teachers and Teaching: theory and practice, v. 15, n. 1, p. 59-85, 2009.

SENO, J. P.; KAPPEL, L. B.; VALADÃO JÚNIOR, V. M. As percepções do professor universitário da área de gestão acerca das mudanças na educação superior: uma pesquisa com profissionais de instituições de ensino privadas do Triângulo Mineiro. Gestão \& Regionalidade, v. 30, n. 88, p. 49-61, 2014.

SILVA, A. B.; COSTA, F. J. Itinerários para o desenvolvimento da competência docente na pós-graduação Stricto Sensu em Administração. Revista Economia \& Gestão, Belo Horizonte, v. 14, n. 34, p. 30-57, 2014.

SIQUEIRA, D. S. P. Administração - Há Vagas: expansão do ensino superior privado na Região Metropolitana de Salvador (1994 - 2000). 2001. 137 f. Dissertação (Mestrado em Administração) - Universidade Federal da Bahia, Salvador, 2001.

SOUZA-SILVA, J. C. Aprendizagem organizacional: desafios e perspectivas ao desenvolvimento de comunidades de prática. Salvador: Editora Conhecimento Superior, 2007.

SOUZA-SILVA, J. C.; DAVEL, E. Concepções, práticas e desafios na formação do professor: examinando o caso do ensino superior de Administração no Brasil. Organizações e Sociedade, Salvador, v. 12, n. 35, p.113-134, out./dez. 2005.

TAKAHASHI, A. R. W. Cursos superiores de tecnologia em gestão: reflexões e implicações da expansão de uma (nova) modalidade de ensino superior em administração no Brasil. Revista de Administração Pública, v. 44, n. 2, p. 385-414, mar./abr. 2010.

TEIXEIRA, J. J. V.; LEFEVRE, F. Significado da intervenção médica e da fé religiosa para o paciente idoso com câncer. Ciência \& Saúde Coletiva, Rio de Janeiro, v. 13, n. 4, p.12471256, jul./ago. 2008.

TORDINO, C. A. Formação interdisciplinar de professores de Administração. Revista de Ciências da Administração, Florianópolis, v. 10, n. 20, p. 95-115, jan./abr. 2008.

WHALE, D. Technology Skills a Criterion in Teacher Evaluation. Journal of Technology and Teacher Education, v. 14, n. 1, pp. 61-74, 2006.

ZARIFIAN, P. Objetivo competência: por uma nova lógica. São Paulo: Atlas, 2001.

Data de submissão: 01/08/2016.

Data de aprovação: 16/01/2018. 